\title{
Wellness as a virtue in Health Sciences students: are they practising what they preach?
}

\begin{abstract}
"Moral excellence, a positive trait or quality deemed to be morally good and valued as a foundation of principle and good moral being. Personal virtues are characteristics valued as promoting collective and individual greatness"
\end{abstract}

Collective and individual greatness are keystones of Health Science education. Enabling prospective healthcare providers to better the quality of life of the population they serve is vital to ensure collective greatness. However, collective greatness can only be achieved once a student is able to attain and retain individual greatness. Self-care, a necessary human regulatory function under individual control, is part and parcel of individual greatness. Healthcare providers can only care for others once they have established, and are able to, care for themselves.

The changeover from school to university remains challenging. Attending university for the first time is often associated with poor eating patterns, a lack of physical activity and chronic stress. ${ }^{2}$ Medical or Health Science education has been well documented as being physically and emotionally taxing. High levels of stress associated with intense academic pressure can impair student behaviour, and are not conducive to a successful learning environment. A drastic decrease in the level of physical activity, sleep deprivation, increased peer pressure in terms of alcohol and tobacco use, and, for the first time, being self sufficient in terms of cooking and procuring food, coupled with budget constraints, can negatively impact on the health and well-being of students. ${ }^{3,4}$

Research conducted at the School of Medicine, Indiana University, Indianapolis, USA, showed that first-year medical students demonstrated marked changes in health habits as they adjusted to student life. A distinct increase in alcohol consumption, reduced physical activity and increased socialisation resulted. All of these are predictive of emotional and academic adjustment. And even though the educational intervention showed promise, the study highlighted the importance of self-care when coping with emotional and academic stressors. ${ }^{5}$ It was found in another study, conducted on 963 matriculating medical students, residents and attending physicians, that medical school training could inhibit students from making healthy choices and maintaining healthy behaviour. Residents tended to exercise and sleep less, and the authors concluded that if physicians did not practise these healthy habits, they are less likely to promote such activities to their patients. ${ }^{6}$

The findings by Gresse et al, published in this issue of the SAJCN on eating, drinking and physical activity in Health Science students, compared to that in other students at a South African university, suggest that Health Science students do not follow a healthier lifestyle than other students. ${ }^{7}$ On a positive note, the only differences between the groups were that fewer Health Science students consumed alcohol to the point of binge drinking or passing out, and that they also reported lower consumption of stimulant-containing energy drinks. However, the male Health Science students reportedly consumed less vegetables. The general lack of healthy eating habits in all of the students, especially in terms of a lack of dairy, fruit and vegetable intake, as well as the high prevalence of fast food intake, was evident from the study. Half of the students (Health Science and other) did not consume breakfast for five days of the week. This can directly impact on concentration, and in turn, academic performance, and the acquisition of practical skills necessary to treat patients. An alarming percentage of the students in general (78\%), and also the Health Science students, were physically inactive. This is a definite cause for concern if the significant benefits of physical activity, in terms of productivity, creativity, relaxation and overall health and well-being, are taken into consideration.

Although the results from the study cannot be generalised because of the small sample size, lack of diversity in the sample size, and only being localised to one medical school, the study highlights the importance of well-being of specifically health science students and the implications of the lack of awareness of health and wellbeing. Twofold recommendations (practical application and for future research) emanate from these findings. Self-care should form part of the core curriculum of Health Science students in terms of practical application. The topics addressing self-care in the core curriculum should address physical inactivity, time management, study skills, financial planning, healthy eating and stress management.

Wellness programmes which target students and provide them with the necessary resources, such as a recreational settings, healthy meal options, activity centres and support groups, and which promote initiatives, such as a tobacco-free campus, can serve to address these issues. Recommendations for future research should be to limit the collection of baseline information (as this is evident from the literature, and does not solve the problem that we know exists), to focus on interventions and measure the success of the interventions. Faculties and universities will demonstrate commitment to such programmes if it can be demonstrated that the situation is alleviated through the implementation of these activities and the associated activities. Commitment could be achieved either through strengthening the wellness programmes or revising curriculums in order to include health and wellness, and, more importantly, self-care, as part of the education.

Implementing the suggested wellness activities and programmes at faculty or university level would ultimately improve individual wellness and academic performance, and therefore individual 
greatness. By better taking care of the carers, collective greatness will be ensured by improving the healthcare provider-patient relationship, and resulting in wellness as a virtue, not only in Health Sciences students, but ultimately in the healthcare providers who they will become.

\section{Sunita Potgieter, $\mathrm{PhD}, \mathrm{RD}(\mathrm{SA})$, Lecturer}

Therapeutic Nutrition, Division of Human Nutrition, Faculty of Medicine and Health Sciences, Stellenbosch University

E-mail: sunita@sun.ac.za

\section{References}

1. Virtue. Wikipedia [homepage on the Internet]. 2015. c2015. Available from: https:// en.wikipedia.org/wiki/Virtue

2. Holm-Denoma JM, Joiner TE, Vohs KD, Heatherton TF. The "freshman fifteen" (the "freshman five" actually): predictors and possible explanations. Heath Psychol. 2008;27(1 Suppl):S3-S9.

3. Lee J, Graham A. Students' perception of medical school stress and their evaluation of a wellness elective. Med Educ. 2001;35(7):652-659.

4. Rash CL, Malinauskas BM, Duffrin MW, et al. Nutrition-related knowledge, attitude, and dietary intake of college track athletes. The Sport Journal. 2008;11(1):48-54.

5. Ball S, Bax A. Self-care in medical education: effectiveness of health habit interventions for first year medical students. Acad Med. 2002;77(9):911-917.

6. Hull S, DiLalla L, Dorsey J. Prevalence of health-related behaviors among physicians and medical trainees. Acad Pshychiatry. 2008;32(1):31-38

7. Gresse A, Steenkamp L, Pietersen J. Eating, drinking and physical activity in Faculty of Health Science students compared to other students at a South African university. 2015;28(4):xx-Xx. 